\title{
O escritor-escrevente no Educador extemporâneo: um jogo possível
}

The writer-scriptor in the nontemporal Educator: a possible game

\author{
Gabriel Torelly* \\ Universidade Federal do Rio Grande do Sul \\ Paola Zordan** \\ Universidade Federal do Rio Grande do Sul
}

Resumo O texto lança questões as quais não responde, a fim de pensar, com Barthes e Calvino, os problemas da linguagem nas formalizações da escrita educacional. Faz uso de A lógica do sentido, de Deleuze, para tratar a escrita como jogo atemporal e poético. Em sua tradução, os signos escreventes transportam os textos aos múltiplos papéis do escritor-autor, do escritor-escrevente, do escrevente-educador em busca das possibilidades da linguagem. O caráter monstruoso com que se reveste o texto literário frente à linguagem educativa instrumentadora, surge como força que transporta as palavras concretas aos devires autorais. Tais variações colocam em pauta uma ética dos signos que toma as aporias do neutro como mote para perguntas que, propositadamente, são mantidas em aberto.

PALAVRAS-CHAVE: Educador; Linguagem; Paradoxo.

Abstract This text floats questions which it cannot answer, in order to reflect with Barthes and Calvino, on the problems of language in formalizations of educational writing. It uses The Logic of Sense by Deleuze to treat the writing as a nontemporal and poetic game. In its translation, the scriptor signs transport the texts to the multiple roles of the writer-author, the writer-scriptor and the scriptor-educator in a search for possibilities of language. The monstrous character with which the literary text is covered when it faces the instrumentive and educative language, flourishes as a force that transports the concrete words to the authorial becoming. Such variations put on the agenda an ethic of sings that considers the aporias of the neutral as a motif for questions that are, purposefully, maintained open.

KEYWORDS: Educator; Language; Paradoxe. 
Caía-se assim, indefinidamente, por um tempo indefinido (CALVINO, 1992, p.115)

Desde o início, o que está em jogo é a experimentação de uma impossibilidade do que vem a ser pesquisar escrituras e educar junto com a escrita, suas multiplicidades de textos e autores. É importante que o "impossível” seja assumido, desde o primeiro gesto escritural, como a palavra que designa uma instância de virtualidade latente, a presença de uma ausência produtora e eficaz na elaboração de processos semióticos. "Impossível" é o lócus onde os sistemas simbólicos prescritivos encontram uma zona limite de significação e simplesmente derivam junto aos mecanismos arbitrários que articulam o fluxo memorial e os processos textuais (BLANCHOT, 2011, p.38). O que se propõe, portanto, é a experimentação do próprio giro intransitivo da escrita educadora como uma rotação de práxis enunciativas e das múltiplas posições possíveis de um sujeito educador paradoxal, impessoal, ainda que ancorado provisoriamente e performaticamente no nome de algum autor. Esse exercício de ativação de um processo textual autotélico, múltiplo, provisório, dobrado e esgotado sobre si, encontra sua área de pertinência ética e filosófica na esteira da seguinte situação contextual: aquela desdobrada pelos precursores da poética moderna e mais tarde entendida como a insuficiência e em seguida a necessidade de prolongamento do "projeto estrutural" através da "atividade de escritura" (BARTHES, 2004, p.102-104; 2012, p.8). O jogo dos elementos interpretantes que compõe o texto ocorre entre um impossível a ser experimentado e uma tarefa que ainda assim deve ser realizada, ou a única alternativa restante quando a distância assintótica que separava o uso da linguagem e a prática da escritura aproxima-se do grau zero. Jogar nesse campo paradoxal é desconfiar do lugar metalinguístico ocupado pela tarefa educativa de todo aquele que escreve, procurando desarticular a temporalidade crônica e lírica na qual se distribui a docilidade de uma linguagem instrumental e de um sujeito autor, ainda que esse exercício somente se efetue ao preço de uma agonia psicolinguística prolongada.

O ambiente discursivo é saturado numa espécie de cerimonial que intenciona, ironicamente, seu sucesso. Capturada pelas núpcias entre um autor funcional e um contexto estrutural, a leitura inicia presa ao casamento inestético das intenções psicológicas e das reduções sociológicas, essas totalmente implicadas no bem intencionado discurso educacional. ${ }^{1}$ Seguindo o curso das intenções e das reduções, o caminho seria apresentar um autor, sua trajetória política, a inegável contribuição que seus escritos trouxeram para importantes movimentos de época. Da inocência de uma biografia laudatória aos exercícios de enquadramento crítico de uma obra no registro das historicidades, o que se perde, todavia, é o texto. A textualidade requer um ser que foi ontologicamente tragado pela página, aprisionado enquanto fonte de enunciação num campo de permutações irregulares onde ele é privado das correspondências usuais e da rede dos significados monológicos: "as luzes da estação e as frases que você lê parecem mais incumbidas de dissolver as coisas do que de mostrá-las, tudo emerge de um véu de obscuridade e névoa" (CALVINO, 1999, p.19).

$\mathrm{O}$ que um pesquisador, criatura miniaturizada perante certas regras "verdadeiras", lê nas brumas que dissipam a nitidez das certezas e não permitem que uma pesquisa alcance o sucesso de resultados verificáveis peremptórios? Pesquisadores que 
escrevem, escritores pesquisadores, pesquisadores que educam, educadores artistas, historiadores tomados como romancistas, romancistas que se valem da filosofia, filósofos que parecem poetas, poesia maldita, escritores que não se enquadram em gêneros, em escolas, em "ismos" definidos: os papéis não se subsomem ao esperado. Deleuze e seus "precursores sombrios", tensionados com Barthes e todos que, ao se deixarem conduzir pelos problemas da linguagem, racharam coisas e palavras no exercício da criação de textos não fechados e saturados num regime, demonstram, em sua produção, o problema aqui abordado. Tratam-se de textos que jamais se outorgam certeiros, articulando a "verdade" perante miríades de possíveis. Embora existam extração de constantes e regulações dominadoras que se fazem valer textualmente, não podemos restringir o que se abre ao múltiplo reservando "a variação para tipos determinados de língua"(ALMEIDA, 2003, p. 103), visto todas as linguagens, em graduações distintas, darem margem a potenciais variações. Junto a essa potência que permite que uma língua gagueje, varie, tropece e voe com textos "feiticeiros", os quais mais encantam do que afirmam, regimes discursivos são colocados em suspensão.

Subsumido no labirinto interior de tantos possíveis tornados texto, o que se pode é intuir que a maneira mais atenta de ler é traduzir, e que traduzir não significa o gesto servil de fidelidade estrita ao significado, mas o modo de experimentação de um tom, um "tônus" que se descobre ao revolver as entranhas do original por meio de uma "reimaginação" ativa (CAMPOS, 2013, p.8, p.14; CORAZZA, 2012, p.183). O que se busca no texto é a vertente do ritmo, uma intensidade de palpitação, ou como ele é capaz de obedecer a um pulso de linguagem, a uma espécie de batida que ressoa enquanto se escreve. Mosaico de combinações semióticas de onde se desprende um caráter léxico, encantatório e musical, o texto atualiza latências e pulsações que não vêm da razão e que fazem com que o discurso e a sintaxe se organizem em função não apenas da transmissão de uma mensagem, mas da criação de uma atmosfera, de uma aura. Procurando arrancar tonalidades dessa atmosfera para submete-la a um processo de estudo e recriação, eis os termos da hipótese que ora se apresenta: pesquisar a tonalidade de um texto não é somente um exercício de ordem semântica ou documental, mas algo relacionado àquilo que Roland Barthes (2004, p.116) definia como a própria "ética do signo" - modo particular de reivindicar através da escritura um espaço de "alteridade total", uma reserva inequívoca com relação ao sentido. $\mathrm{O}$ tom produzido por um escritor é como uma espécie de roupagem lançada sobre um impulso criador extralinguístico, maneira de tecer no interior da linguagem o propósito do seu próprio desmoronamento e atualizar uma linhagem de forças involutivas que operam desde a obra de Nietzsche no sentido de produzir efeitos plásticos de latência ou esquecimento. Ao tônus desenvolvido pela escritura corresponde uma determinada ética dos signos, esta mesma que cumpre explorar através de uma atividade pesquisadora inerente à formalização de um discurso educativo.

Os signos aqui são tomados como força extralinguística entre o que se vê, o que se sente, o que se ouve e as estruturas de uma linguagem. Um signo traz o incorporal do que é não sendo a coisa, pois, mesmo Agramatical, opera enquanto "noção filosófica que põe em jogo o funcionamento positivo, sobretudo intensivo, da linguagem" (ALMEIDA, 2003, p.29), mostrando que o "ser da linguagem" é ser incapaz de dizer o lugar da coisa, e mesmo assim continuar dizendo alguma coisa. Assim, atualiza 
e radicaliza o enigma das "máquinas de matar o silêncio" (CALVINO, 1999, p.33), ou ainda, a "aporia do neutro", tal como formulada por Roland Barthes: o impossível que ainda sim deve ser praticado quando a indistinção entre o escritor e o escrevente cristaliza-se no interior da linguagem (2003, p.142).

\begin{abstract}
O escritor-escrevente é um excluído integrado por sua própria exclusão, um herdeiro longínquo do Maldito: sua função na sociedade global não está talvez muito longe daquela que Claude Lévi-Strauss atribui ao Feiticeiro: função de complementaridade, já que o feiticeiro e o intelectual fixam de certo modo uma doença necessária à economia coletiva da saúde (BARTHES, 2013a, p.38-39).
\end{abstract}

Roland Barthes e Italo Calvino não são palavras que representam a priori o sistema codificado de uma obra, ou simplesmente uma chave de leitura representativa, mas meios intensivos onde o jogo dos signos se recusa a gerar zonas estáveis de identificação. A palavra "jogo" não funciona como um acaso, mas como a própria (anti) lei pela qual os lances do significado são obrigados a retornar ao "campo feiticeiresco" (CALVINO, 1990b. p.140), atemporal, turbilhonar, onde a aporia coisal da linguagem ainda não foi resolvida por um gesto de ordenação. Semiotropia organizada. Fonte virtual de sustentação e de manifestação de uma "ausência" secante e eficaz. Atividade persecutória de um efeito, um processo e um valor de texto. O jogo nos aproxima da polissemia do texto, ao mesmo tempo em que nos distancia da busca por uma constante psicológica de interpretação.

A partir da categoria bastarda do escritor-escrevente, propõe-se então um mote que não é o logos decifrador do real, mas o ludus explorador dos processos de atualização textual. "Função xamânica", antes de função autor. Trata-se, portanto, de pesquisar a pluralidade de atualizações semânticas de um modus operandi criativo, a ética dos signos decorrente de um tônus escritural, de uma diferença específica e intensiva introduzida na linguagem. Partindo dessa perspectiva, a problemática, aqui ainda não desenvolvida em sua totalidade, se desdobra ao menos em três situações: 1) Barthes e Calvino são atraídos por uma operação semelhante de neutralização do significado, percorrendo um campo escritural investigativo que põe em cena uma determinada ética dos signos; 2) Calvino e Barthes não param de trocar de lugar, alternando os papéis do escritor e do escrevente, sem jamais deixar que essa oposição se resolva em síntese ou se cristalize em sistemas fechados; 3) desse tônus crítico-poético onde coexistem o instrumental e o escritural é possível extrair potência intelectual para a invenção de uma escrita educacional extemporânea não formalizadora. Contudo, fora de um tempo "com", do tempo contado, significado em dias, o intempestivo da "precondição" embriagada que Nietzsche coloca como afeto sine qua non para que exista a arte (NIETZSCHE, 2006, p. 67-68), temos intuições que definem "o que é bom e o que é mau" fora das graduações morais impostas pelos rígidos "músculos" do passado (NIETZSCHE, 2000). Romper com as estruturas estratificadas pelo tempo, nas relações que instituem a educação enquanto apreensão de textos classificados como "bons", mas assimilados nas instituições educacionais a contragosto, implica a busca de escritos alheios ao que as tradições e erudições elegem como "necessário" a uma cultura. Trata-se de se deparar com escritas que tragam o caráter extemporâneo do escrevente de modo a se pensar a educação, intrínseca a todo texto, pelos devires atemporais que, 
sem fechar sistematizações, joga com as forças feiticeiras dos signos inclassificáveis.

Vamos supor que escritores sejam meios de dispersão dos significados, e não sujeitos preenchidos pela cumplicidade de uma intenção. Um meio aberto pela escrita pode ser visto como bom ou mau em virtude do gradiente de virtualização que suscita. Nesse registro, pesquisar a ética dos signos percorrida por escritores equivale a ingressar em meios intuitivos de dispersão: acelerar o fluxo de matéria para entrar nos túneis imaginários de Cortázar ou multiplicar as vias de entradas para o real sob efeito dos palácios rarefeitos de Borges. Não se trata de negar os vestígios particulares que as estruturas deixam no tecido da escrita, nem as possíveis marcas analógicas deixadas no texto pela história psicológica do autor, mas preferir, por um misto de gosto ético e estético, instalar-se conceitualmente em outro lugar. Não num fora absoluto, mas numa reserva estratégica do discurso, onde o sentido e o não-sentido se intercambiam sem cessar. "Adentro, afuera: eso realmente no importa" (CASTANEDA, 2012, p.175). No interminável salão da linguagem então, onde soa o embalo de um duelo infinito e a fronteira entre o dizível e o indizível se transforma em enigma potencial do poético. Ariano exprimia a problemática da aporética escritural mais ou menos assim: "entre o Sol e os cardos, entre a pedra e a Estrela, você caminha no Inconcebível. Por isso, mesmo sem decifrá-lo, tem que cantar o enigma da Fronteira, a estranha região onde o sangue se queima aos olhos de fogo da Onça-Malhada do Divino. Faça isso, sob pena de morte! Mas sabendo, desde já, que é inútil” (SUASSUNA, 2012, p.306).

Desalojado do seu lugar privilegiado de enunciação pelo funcionamento heteróclito e maquinal dos regimes de significação, o sujeito-autor se torna uma substância esquartejada pelos efeitos de sentido obtidos numa batalha audiovisual. "Na singularidade dos paradoxos nada começa ou acaba, tudo vai no sentido do futuro e do passado ao mesmo tempo" (DELEUZE, 2011, p.82), de modo que como figura de traços duvidosos compostos e recompostos a partir dos resultados de jogos estereotípicos, um sujeito pode finalmente aparecer enquanto produto parcial dos modos móveis e relacionais de correspondência entre o que se vê e o que se diz. Também pode surgir como resultante de um processo de pulverização da essência que permite percebê-lo como uma mistura combinatória, filho bastardo de uma nova disposição dos fatores físico-semânticos cujo registro não é mais o das zonas ontológicas purificadas (sujeito/ objeto/Deus), mas o das criaturas híbridas, monstros plásticos intermediários gerados numa zona teratológica de subjetivação (LATOUR, 2013). Como falar a partir daí (falar?), ou ainda, como criar e movimentar uma escrita educadora situado nesse lugar extemporâneo?

Com o passar do tempo, os papéis não são exatamente os mesmos de antes; sem dúvida a ação que estes levam adiante por meio de intrigas e reviravoltas conduz a algum tipo de desfecho final, que continua a se aproximar mesmo quando a intriga parece complicarse cada vez mais e os obstáculos parecem aumentar. (CALVINO, 1990, p. 77).

Um meio de dispersão seria aquele que se mostra suscetível a um alto índice de derrapagem audiovisual, à configuração de novas misturas ou combinatórias que desorganizam o reinado transitório e metamórfico das estereotipias cristalizadas 
na linguagem. Roland Barthes desde muito cedo se instalou aí, na pulsação ética e escritural regida por esse ponto de dúvida que fica suspenso entre o vazio da palavra e a transparência da tagarelice. Explorando modos de habitar essa zona intempestiva (vazia?), postulou a homologia entre o tempo da linguística e o sistema temporal do discurso. O "terceiro termo" da linguística, por exemplo, indicaria um "estado neutro e inerte da forma", um "estilo da ausência que é quase uma ausência ideal do estilo" (BARTHES, 2004b, p.65-66). O "estado neutro", transportado por Barthes da esfera da linguística para o domínio do discurso, indicaria a insistência de uma reserva exterior ao paradigma, de um campo de intensidades não-paradigmáticas atuando como zona de fermentação autopoiética. Por um lado, um escândalo científico. Por outro, uma nova possibilidade formal: instalar-se nessa enigmática e clandestina região parasitária das estruturas denominada "sintaxe virtual". Surge então uma espécie de aventureiro que não reconhece os termos da armadilha dialógica e cavalga o flanco selvagem do sentido à espera pela ocasião oportuna de mostrar-lhe a língua: é o texto quem aparece como "essa pessoa desenvolta que mostra o traseiro ao Pai político" brincando de realocar no espaço os fragmentos de um objeto vazio (BARTHES, 2013, p.63).

Escandalizada, a escrita quer escapar à dimensão estrutural da ciência dos signos para ingressar em sistemas de perversão; baldar a arrogância da fala através de uma estratégia poética escritural onde um ser andrógino é capaz de ingressar na zona de enunciação ao mesmo tempo em que contorna a tendência classificatória arborescente dos gêneros. Projeta-se a sombra de um paradigma virtual: zona de composição e decomposição onde as palavras produzem ecos imaginários, rebatem-se entre si num jogo de espelhos quebrados, percorrem velocidades distintas até se aproximarem perigosamente a um grau zero de saturação - o que não é expressão de um sintagma congelado, mas do próprio movimento de degelo das polaridades. Algum tipo de recombinação aleatória dos dados da experiência produz uma anulação temporária do sistema analítico-antropológico de metadados que criava a oposição assimétrica entre o moderno e o não moderno. A selvageria dos trópicos invade o laboratório. Nós e Eles? Identidade e Alteridade? Isso realmente não importa. O hibridismo se apresenta, e a literatura ressurge da lama como a única instância que jamais lhe renegou. Depois de denunciar o caráter "apofático" da "semiologia negativa" e o "abuso epistemológico" que sustenta uma relação de identificação entre ciência e metalinguagem, Barthes dá início ao projeto de uma "semiologia ativa", ou "semiotropia", visando corrigir os efeitos do abuso e promover o encontro entre a força generalizante do método semiótico e a singularidade da linguagem que se toma enquanto objeto escritural. "A ciência é grosseira, a vida é sutil, e é para corrigir essa distância que a literatura nos importa"; a literatura: verdadeira "mestra de nuances" (BARTHES, 2003, p.27; 2013, p.19, p.3841; 2013b, p.71). Agora já podemos perguntar: de que modo um determinado tônus escritural se apresenta inicialmente enquanto fonte de uma discursividade contra ontológica, e em seguida como meio de dispersão de uma ontologia universal numa multiplicidade de ontologias menores?

É possível pensar uma forma, talvez a última das fórmulas: habitar o hábito de estar morto; viver como em Eusápia, Argia, Adelma (CALVINO, 1990). Adentrar um espaço intermediário de tensões indefinidas, "fruto de uma reflexão ponderada, não de caprichos passageiros” (CALVINO, 1990, p.102) ou de processos infinitesi- 
mais onde as perigosas fantasias da identidade esbarram na neutralização dos seus piores avatares. Nesse ponto, o sujeito já não encontra a sua coisa pegajosa e aderente: pois ali ela se desfaz, atraída para fora de si e do cordão transcendental por um misto de agonia e perversidade. São instantâneos de autoimolação, de concentração furtiva numa estranha espécie de eternidade não eterna. Uma encruzilhada imaginária e real, onde esses dois termos carregados de complacência não têm permissão para entrar em jogos retóricos de oposição; onde o movimento cursivo do carvão grifado sobre a página remete ao estado de espírito de um samurai saído dos jardins de Kyoto, ou ao minimalismo dos rituais do chá praticados nas bordas do deserto do Mali. Aquilo que antigamente podia aparecer sob a forma de um "exotismo", hoje emerge como o "dispositivo central de todos os coletivos" (LATOUR, 2013, p.102).

O duplo da fantasia já não funciona como o "ser", mas somente como outro disfarce, um insondável labirinto de carapuças sem fundo: a moral do ser devorada por uma ética da trapaça multiplicadora. $O$ que acontece se a função transcendente for substituída por uma rede de trapaças ou por uma diabólica arte combinatória politemporal e parapsicológica? Que novela é essa na qual o que está em tela é apenas a multivalência dos níveis antinarrativos? Romance de um Anti-Romance? O que ocorre fora da grande arapuca platônico-aristotélica pela qual o Mesmo se cola no Outro e transmite seus rastros pela eternidade? Os operadores de síntese ruíram: o Deus-Providência, ou as variadas modalidades de estruturas narrativas analógico-teleológicas já não são capazes de aglutinar em torno de si o sentido das práticas. Os mestres da finalidade da existência zarparam para outras praias quando as ondas descontínuas anunciadas por Michel Foucault inundaram o porto da epistemologia moderna e arrancaram suas pilastras de auto reprodução (FOUCAULT, 2008). No desenrolar da tormenta, coletivos selvagens acendem uma fogueira na beira da praia. Um festim inicia-se. Alguns ameaçam insuflar um vento de destruição no interior (rígido?) das estruturas. Outros mergulham em laboratórios fantásticos onde se gestam novas misturas e um complexo infra-humano de micro ontologias experimentais.

Embora teorize como poucos acerca do funcionamento e do efeito das estruturas, Deleuze está, evidentemente, interessado em outra coisa: naquilo que foge, escapa, emperra uma regularidade de Arquivo, turva uma auto evidência do discurso. No desmoronamento de uma emanação estrutural, o interesse recai sobre o sistema de perversão que se imiscui no lapso de sua ausência. Bulbos de perversidade inventiva. É neste ponto que se pode situar o desabrochar de uma nova problemática: a estrutura, seja de que espécie for, funciona ao modo de um negativo, cujo efeito paradoxal é gerar a própria exterioridade que lhe é imanente. Mas o que é esse exterior? Como operar a partir dessa fissura aberta na carapaça do sentido? Enigma de uma pesquisa que se situa ao mesmo tempo em que escava esse lugar atópico "pós-estrutural", onde a dissidência não é uma dialética, mas uma ética que necessariamente se recurva sobre a linguagem e sobre si. As unidades que revestem a batalha audiovisual travada entre o visível e o enunciável estão expostas. Uma pausa se introduz nas entrelinhas da discursividade ocidental, mas o silêncio não agrada. Como recusar o neodogmatismo que se esconde no silêncio sistemático e ao mesmo tempo não retornar à arrogância da linguagem que se reproduz sem conjurar seus efeitos totalizantes? Entre os possíveis 
oferecidos por uma espécie de modalidade oriental de silêncio e a ingenuidade da palavra arrogante deve haver um tom que seja capaz de levar o gesto e a fala até um outro lugar, eis o ponto invisível, impossível, visado pela atividade de uma escrita educadora.

Desembarcando numa paisagem contemporânea, cuja nova geologia moral é resultado de uma tempestade de signos, a escrita educadora encontra hoje condições e matéria para se portar como um Robinson Crusoé às avessas. O surrealismo ontológico pressiona as bordas do realismo sociológico como uma máquina de produzir mundos que escapam às políticas governamentais do texto e da vida. A literatura deserta do corredor teleológico asfixiante da narrativa iluminista reiterada no positivismo da Escola Moderna, explode em fragmentos e dispersões no papel contemporâneo que procuram fixá-la. O teólogo dá um trago prolongado num cigarro de ópio e experimenta o pathos esotérico de um transe místico radical. A poesia deriva até a carnadura incandescente da coisa linguageira. $\mathrm{O}$ sublime se faz rasteiro. A astúcia retórica e a arrogância velada dos processos semióticos de formalização de valores e valências de escrita, antigamente naturalizados, se fazem visíveis enquanto forçosas naturalizações do que, desde sua gênese, se desvia do natural. Há uma tensão onto-linguística borbulhando na superfície do discurso que tenta encontrar seu ser. As proposições que desdobram horizontalmente uma narrativa já não podem afastar-se tão facilmente do seu ponto de arranque. Nesse caldo contextual onde o universo é infinito e a referência é móvel, há, todavia, uma proposição de aparência válida que poderá servir como ponto de partida: ninguém virá nos buscar: nem Deus, nem o Pai, nem a Mãe, nem o Estado, nem o Mercado, nem as Psicologias, nem a Crítica, nem a Análise, nem as Sociologias da Reprodução, nem a Educação para a Diversidade, Nem, Nem, Nem... O método, por assim dizer, é ficcional por necessidade. Não há alternativa.

Em "O Cavaleiro Inexistente" circula um personagem que já não encontra lugar entre a essência sem corpo e a matéria sem ideia (CALVINO,2005). Traduzindo o procedimento de Barthes, poderíamos criar e explorar as implicações éticas e estéticas de um postulado homológico entre o personagem do romance e o espaço problemático ocupado por um Educador inexistente (Imaginário? Real? Pouco importa). O Educador inexistente como o único lugar habitável quando se desfaz o bang-bang dualista da história da filosofia. Desfeitos os termos do bang-bang, o que resta é o cavaleiro percorrendo uma espécie de "velho oeste" da linguagem, obrigado a ocupar o polimorfismo de um lugar de sujeito a um só tempo vazio e renascente. Criatura híbrida, monstruosa, privada de outros movimentos que não sejam o de seguir a "cauda fantasmática da realidade" (BARTHES, 2013b, p. 56). Seu problema não é mais o de encontrar a fonte da vida eterna, mas o de saber multiplicar as mortes e se entregar sem trégua à vagabundagem dos circuitos mentais heterotópicos. $O$ único realismo concebível é o que "busca no real o outro misterioso da realidade" (CORAZZA, 2012, p.18).

O cavaleiro atualiza a necessidade do galope. Mesmo que o terreno se assimile ao de uma cidade invisível, ele põe em marcha um estratagema: não há um império do texto, nem a tirania de uma escrita protocolada, mas o desenrolar extensivo de uma jogatina metódica: armadilhas, suspense, produção de uma fina superfície de contato onde o médico e o monstro trocam infinitamente de lugar: a linguagem e a ausência, a ausência na linguagem. Enquanto procedimento ou operação, propõe 
a investigação de um corpus delimitado. Enquanto movimento de texto, inventa os traços constitutivos de um Educador inexistente que se constitui através do próprio exercício da escrita. $\mathrm{O}$ efeito de texto corrige os excessos do efeito protocolar da escrita e a recíproca certamente será verdadeira. Uma duplicidade é responsável por organizar os elementos metodológicos: de um lado, a sistematicidade de um corpus; de outro, a abertura e a imprevisibilidade. "É preciso ser dois para ser louco, somos sempre loucos em dupla, ambos se tornam loucos no dia em que "massacraram" o tempo, isto é, destruíram a medida, suprimiram as paradas e os repousos que referem a qualidade a alguma coisa de fixo" (DELEUZE, 2011, p.82).

Como em O visconde partido ao meio (Calvino, 2011), o recorte e a complementaridade se justificam menos em virtude dos nomes e da sua inscrição numa história da literatura e da crítica literária do que em função de um gesto e um ritmo impressos na própria relação entre vida, texto e linguagem. Tal ritmo permite a libertação das forças que afirmem "a pluralidade das linguagens como garantia de uma verdade que não seja parcial” (CALVINO, 1990b, p.131). Barthes e Calvino formam o verso e o reverso de um mesmo processo; atualizam uma mesma ética dos signos; dão corpo a um problema de escrita capaz de dar desenvoltura aos movimentos de um Educador inexistente desembarcado numa paisagem extemporânea. Ao nos lançarmos numa "corrida louca, em que giramos em círculo" (DELEUZE, 2011, p. 35), jogamos com o infinitivo puro não determinado do tempo dionisíaco, sem passado, presente ou futuro.

Nesse jogo, "sem regras, sem vencedores nem vencidos, sem responsabilidade” (DELEUZE, 2011, p.63), se escreve para liberar a vida justo onde está aprisionada, a fim de fazer da vida algo mais do que uma cronologia pessoal pautada por erros e acertos. Jogando com uma escrita cujo devir incontável, não computado no discurso instrumentador, impermeável às palavras de ordem das enunciações peremptórias, o Educador extemporâneo afirma o sentido paradoxal de um tempo que "representa o extraproposisional de todas as proposições possíveis ou o conjunto de problemas e questões ontológicas que correspondem com a linguagem" (DELEUZE, 2011, p.221). $\mathrm{O}$ que se consegue, no devir de um discurso que o senso comum considera desarrazoado e não apropriado para a Educação, afirma uma linguagem em aberto, poética, arrastada ao impossível da interpretação e à significações sempre cambiantes.

\section{Referências}

ALMEIDA, J. Estudos deleuzeanos da linguagem. 1a. Ed. Campinas: Ed. UNICAMP, 2003.

BARTHES, R. Aula. 1ª. Ed. São Paulo: Cultrix, 2013.

BARTHES, R. Crítica e verdade. 3a ${ }^{a}$. Ed.São Paulo: Perspectiva, 2013a.

BARTHES, R. O prazer do texto. 6a . Ed. São Paulo: Perspectiva, 2013b.

BARTHES, R. O grão da voz. 1ª. Ed. São Paulo: Martins Fontes, 2004.

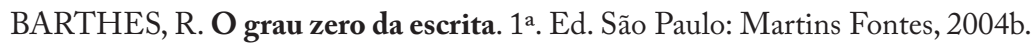

BARTHES, R. O neutro. 1ª. Ed. São Paulo: Martins Fontes, 2003.

BLANCHOT, M. O espaço literário. 1a ${ }^{\text {a }}$ Ed. Rio de Janeiro: Rocco, 2011. 
CALVINO, Í. O visconde partido ao meio. 1a. Ed. São Paulo: Companhia das Letras, 2011.

CALVINO, Í. O cavaleiro inexistente. 1a. Ed. São Paulo: Companhia das Letras, 2005.

CALVINO, Í. Se um viajante numa noite de inverno. 2a. Ed. São Paulo: Companhia das Letras, 1999.

CALVINO, Í. As cosmicômicas. 1a. Ed. São Paulo: Companhia das Letras, 1992.

CALVINO, Í. As cidades invisíveis. 2a. Ed. São Paulo: Companhia das Letras, 1990.

CALVINO, Í. Seis propostas para o próximo milênio. 3a. Ed. São Paulo: Companhia das Letras, 1990b.

CAMPOS, H de. Transcriação. 1a. Ed. São Paulo: Perspectiva, 2013.

CASTANEDA, C. Relatos de poder. 1a. Ed. Buenos Aires: Fondo de Cultura Económica, 2010.

CORAZZA, S. M. Didaticário de criação: aula cheia. 1ª. Ed. Porto Alegre: UFRGS, 2012 (Escrileituras cadernos de notas; 3 ).

CORAZZA, S. M. Os cantos de Fouror: escrileitura em filosofia-educação. 1ª. Ed. Porto Alegre: Sulina, Editora da UFRGS, 2008.

DELEUZE, G. Lógica do sentido. 5a. Ed. São Paulo: Perspectiva, 2011.

FOUCAULT, M. A Arqueologia do saber. 7ª. Ed. Rio de Janeiro: Forense Universitária, 2008.

LATOUR, B. Jamais fomos modernos. 3a. Ed. São Paulo: Editora 34, 2013.

NIETZSCHE, F. Humano demasiado humano. 1a. Ed.São Paulo: Companhia das Letras, 2000.

NIETZSCHE, F. O crepúsculo dos ídolos (ou como se filosofa com o martelo). 1ª. Ed. São Paulo: Companhia das Letras, 2006.

SUASSUNA, A. Romance d'A Pedra do Reino e o Príncipe do Vai-e-Volta. 9a. Ed. Rio de Janeiro: José Olympio, 2012.

Notas

${ }^{1}$ Para uma crítica ao gênero das boas intenções associadas ao discurso educacional aqui mencionado, ver: CORAZZA, 2008.

* Doutorando em Educação no Programa de Pós-Graduação em Educação da Universidade Federal do Rio Grande do Sul, Porto Alegre, Rio Grande do Sul. Brasil..

** Professora do Departamento de Artes Visuais e do Programa de Pós-Graduação em Educação da Universidade Federal do Rio Grande do Sul, Porto Alegre, Rio Grande do Sul. Brasil.

\section{Correspondência}

Paola Zordan - Universidade Federal do Rio Grande do Sul, Faculdade de Educação. Av. Paulo da Gama, 110, prédio 12201. Bairro: Farroupilha. CEP: 90046-900. Porto Alegre, Rio Grande do Sul, Brasil.

E-mail: gabrieltorelly@gmail.com - eveliseportilho@gmail.com

Recebido em 04 de julho de 2016

Aprovado em 03 de outubro de 2016 